\title{
Towards an Integrated Approach to Improving Innovation Management System of Mining Companies
}

\author{
Yuliia Lazarenko, ${ }^{1, *}$, Olga Garafonova ${ }^{1}$, Svetlana Grigashkina ${ }^{2}$, and Irina Verezomska ${ }^{3}$ \\ ${ }^{1}$ Kyiv National Economic University named after Vadym Hetman, 03057, Kyiv, Ukraine \\ ${ }^{2}$ T.F. Gorbachev Kuzbass State Technical University, 650000, Kemerovo, Russian Federation \\ ${ }^{3}$ Kyiv National University of Culture and Arts, 01601, Kyiv, Ukraine
}

\begin{abstract}
The paper is intended to examine core elements of an innovation management system which is aimed at maintaining a company's innovation practices, improving its innovation performance, increasing innovation capacities and hence expanding the opportunities for future innovation-oriented activities on a continuous basis. Based on existing industry analysis reports, it is shown that mining companies need to develop specific innovation capabilities, both internal and external in order to adopt knowledge and devise appropriate innovation-driven growth strategies. As a result of the study, through an integrated approach a descriptive overview of the key components of the innovation management system according to the peculiarities of innovation activities in the mining sector is presented. From a practical perspective the paper provides a framework for the identification of the core managerial areas on which attention should be especially focused in order to increase innovation capabilities and improve innovation performance of mining enterprises in the current business environment.
\end{abstract}

\section{Introduction}

In the modern business reality fast-paced global development has led to a greater role of innovation in maintaining and improving the level of productivity and competitiveness of mining enterprises. These companies especially face difficult choices regarding their profitability, capital allocation, attracting and developing key skills and core competencies as well as effective stakeholder engagement. The complex nature of the environment within which these organizations operate requires therefore increased flexibility and innovation solutions to foster the ability to adapt to rapid fluctuations in the value chain and unpredictable industry changes. In line with this, under the prevailing circumstances across the whole mining value chain innovation has become an objective necessity and a determining factor for economic development instead of non-essential business activity. Consequently, it is obvious that in the current context mining companies should identify

*Corresponding author: yuliia.lazarenko@,kneu.ua 
sources of sustainable advantage, develop strategic innovative thinking skills and use appropriate analytical tools and managerial techniques to face their tough choices. This underlines the need for more systematic innovation management practices, which can be commonly regarded as innovation management systems as a means for the enterprises of the mining industry to improve their innovation capabilities.

The paper is intended to identify core elements of the innovation management system for mining enterprises and outline appropriate managerial aspects within each component. The main purpose is to present a descriptive overview of the key innovation management areas through an integrated approach given the peculiarities of innovation-oriented activities in the mining sector.

\section{Materials and Methods}

Numerous industry research studies conducted of the recent decades throughout the world have demonstrated a broad range of drivers for adopting and adapting innovation in the mining sector. According to their findings, in light of current industry trends mining companies seek, above all, to improve their business productivity, share operational risks, increase the efficiency of deposit discovery, strengthen the technological dimension of production activities, stimulate sustainable growth and hence drive their own development. In addition, with recent commodity price declines and reduced profit margins, it had become urgent and necessary for many enterprises to reduce their operational costs in terms of labor, capital, energy and other expenses [1-4]. However, despite the above-mentioned drivers there remain significant barriers to innovation in this sector which need to be addressed. Evidence shows that main innovation activity problems and challenges specific to the companies of mining industry pertained mainly to increased production costs, a short-term focus on exploration, the difficulties of gaining access to the right type of knowledge and technologies, a conservative attitude towards innovation in the mining sector, a traditional restrictive mindset which may hinder creative thinking and discourage significant organizational changes as well as a lack of employees with the right type of skills required for development and effective implementation of innovation strategies [5]. All of this underscores the need to examine industry-specific factors underpinning the innovation performance and emphasizes the relevance of the appropriate integrated application of modern innovation management tools and techniques on a systematic basis for enhancing the innovative and absorptive capacities of mining companies.

In this context, the study aims to analyze key elements of the innovation management system for the enterprises that operate within the mining industry using an integrated approach and define managerial areas which have a positive impact on the level of organizational innovation capabilities.

The paper is structured as follows: first a descriptive overview of the peculiarities of innovation-oriented activities in the mining sector is provided. Then, based on existing industry analysis reports the specific organizational capabilities of mining companies related to effective implementation of innovation are identified. As a result of the study, through the integrated approach core elements of the innovation management system for mining companies are systematized and appropriate managerial aspects on which attention should be especially focused with regard to modern innovation management trends are presented. 


\section{Results and Discussion}

In recent years challenges in the business environment have forced mining companies to focus on business improvement initiatives and innovative managerial solutions in order to increase the flexibility of processes, gain competitive advantage and maintain sustainable development. Industry trends over the last decades indicate that without significant changes and interventions the mining sector will not be able to overcome present challenges. Innovation therefore can be considered as a crucial factor which has the power not only to impact and address current problems, but also can lead to a more sustainable and economically thriving industry.

An analysis of international experience has shown that competitiveness, costeffectiveness and growth of the mining companies are strongly connected with their innovation activity, which may include research, exploration of new deposits, product development, improvement of existing technology processes as well as innovative changes in organizational structure, corporate culture, current knowledge base and information sources. Research conducted by Deloitte (2016) has suggested that for the companies which operate within the mining sector three main dimensions of innovation practice can be distinguished: core innovations that are aimed at optimizing existing assets, products or services, adjacent innovations which incrementally expand a business in new areas and transformational innovations that can be represented as new inventions for the companies of the industry [1]. Having in view these broad areas, innovation can be considered as a complex issue covering a wide range of exploratory, technological, organizational, social and commercial activities. It also applies to a company's operating structure, management approaches, corporate strategies, stakeholder engagement and a number of other dimensions central to the business. Effective innovation management in the mining industry involves in this context the capability to manage several aspects at the same time in order to improve a company's performance and achieve desired outcomes e.g. maintaining a competitive advantage, increasing operational efficiency, protecting or expanding market share $[6 ; 7]$. With regard to innovation activities, the mining sector due to its highly specific nature is far different from any other industry in the global economy. There are various aspects of operating a business in this sector that should be taken into consideration in creating a statement of differences. It must be pointed out that the innovation process within the mining industry is strongly influenced by external factors such as public regulations and the readiness of the enterprises to embrace new business models. Environmental regulations, for example, force enterprises to seek new technologies, managerial solutions and approaches towards minimizing environmental impacts and providing benefits to the regions in which they operate and therefore to implement open innovation practice and cooperate in innovation projects in order to overcome such challenges.

Describing and analyzing current trends relating to innovation-oriented activities in the mining sector it is necessary to emphasize that given the nature of the industry, mining companies tend to be focused primarily on developing the technological process innovation because advanced manufacturing processes can reduce production costs, shorten the time to market, increase quality and thereby generate higher profit margins, what is crucial for ensuring sustainable growth [8].

In respect of the 'soft' aspects of managing innovation process several industry reports have pointed out the conservative attitude towards innovation in the mining industry and described this sector as an inflexible and technically oriented industry with a focus on efficiency, which is reluctant to adopt radical changes. In this context, it was observed by some industry experts that there is a general problem for mining companies related to a business culture which prefers to use established technologies, tools and procedures and may hinder innovative thinking [9]. At the firm level these factors also contribute towards 
changing attitudes to the preferred strategic approach to the innovation: mining companies due to the nature of the sector in which they operate tend to choose the fast-follower strategy rather than being the first-movers, who face high costs involved in long-term research and development activities and have to deal with competing priorities associated with risks and uncertainties that are inherent in every innovation process.

Against this background it can be assumed, that in order to foster innovation in the mining sector a profound decision-making basis for innovation projects is required, and it starts with an integrated understanding of the complex innovation process as well as providing an innovation management system of a company. From a theoretical viewpoint, the innovation management system comprises a set of interrelated elements which are coordinated in order to provide activities required to maintain the company's innovation practices, improve its innovation performance and hence increase the chances to generate innovation on a continuous basis $[10 ; 11]$. According to the European Innovation Management Standard (CEN/TS 16555-1:2013) the essential components of the innovation management system, which should be taken into consideration in order to innovate effectively are structured around these key areas: context of the organization (including external trends, enabling factors, opportunities and challenges that can impact innovation activities), leadership for innovation and a corporate strategy (top management vision, corporate values and an organizational culture that fosters creativity and innovation), planning for innovation success (innovation objectives and strategies of a company), operations (appropriate innovation management tools and techniques depending on the types of innovation to be adopted), support (specific resources, competencies, communication and collaboration skills necessary to execute the innovation strategies), assessment (methods for monitoring and a system of indicators for evaluating the innovation activities) and improvement of the innovation management system [10].

The core elements of the innovation management system and the most important managerial areas related to these components according to the characteristics of innovation activities in the mining industry are presented in Table 1 (developed by authors adapting [1, $6-9,12-15])$.

Table 1. The descriptive overview of the key elements of innovation management system according to the peculiarities of innovation-oriented activities in the mining sector.

\begin{tabular}{|c|c|}
\hline $\begin{array}{l}\text { Element of the innovation } \\
\text { management system }\end{array}$ & Description of the key managerial areas \\
\hline $\begin{array}{l}\text { The organizational } \\
\text { context }\end{array}$ & $\begin{array}{l}\text { Scan and analyze the external environment of a company } \\
\text { (political, technological and economic aspects with a special } \\
\text { emphasis on community relations and subsequent social } \\
\text { issues), adapt to environmental regulations within the sector } \\
\text { and identify present and future related challenges that can be } \\
\text { crucial for innovation development. }\end{array}$ \\
\hline - Innovation strategy & $\begin{array}{l}\text { Define innovation objectives, devise appropriate innovation } \\
\text { strategies depending on the types of innovation to be adopted } \\
\text { and align them with a corporate strategy. }\end{array}$ \\
\hline $\begin{array}{l}\text { - Innovation culture and } \\
\text { leadership }\end{array}$ & $\begin{array}{l}\text { Create a corporate culture that supports innovation, overcomes } \\
\text { the traditional mindset and contributes to changes in } \\
\text { conservative attitudes towards innovation. }\end{array}$ \\
\hline $\begin{array}{l}\text { Innovation management } \\
\text { tools and techniques }\end{array}$ & $\begin{array}{l}\text { Recruit competent employees with the right set of managerial } \\
\text { skills, implement modern approaches and tools to innovation } \\
\text { management which comprehensively covered both technical } \\
\text { aspects and 'soft' components of innovation process (e.g. social } \\
\text { skills) in order to stimulate creativity and innovation thinking } \\
\text { as well as increase the willingness to adopt innovations. }\end{array}$ \\
\hline - $\quad$ Resource management & Assimilate and acquire resources necessary for innovation, \\
\hline
\end{tabular}


manage employees' competencies, develop specific innovation capabilities at a firm level.

- Knowledge management Provide access to the right type of knowledge, open up innovation processes to allow for the in-flow and out-flow of inventions and technologies and to adopt external ideas, knowledge, skills and competencies for the implementation of innovation projects.

- Innovation performance

Use an appropriate system of indicators to measure innovation assessment and improvement performance and provide a basis for increasing organizational innovation capabilities.

In devising measures to promote innovation capacities of the mining companies, particular mention should be made of certain sectoral specificities related to internal firmlevel factors that determine a company's ability to be effective, efficient and successful in managing innovation. The industry analysis reports have highlighted that many companies in the mining sector have been slow to adopt a corporate culture that encourages the embrace of innovation and ease barriers to creativity, believing that such 'soft' aspects of managing the innovation process are not of decisive importance for their business productivity or future competitiveness [1-4].

It should be noted that for the mining sector innovation practices are not confined to the technological aspect, including for example automation and digitization of manufacturing processes. Along with this, they can be implemented in such alternative forms as ecological or 'clean' innovation (e.g. research and development of cost-effective renewable energy technologies), business innovation (e.g. changes in the company's business model and value chain) and social innovation (e.g. partnerships, networks and approaches to engaging with stakeholders) [3]. According to these arguments, innovation is a multifaceted concept and it is widely recognized that to set up an effective innovation process it is not sufficient from a company's perspective to focus on a single dimension of innovation. The integrated approach to innovation management is of particular relevance in that context because it can provide a framework for developing holistic solutions aimed at improving the innovation performance by combining different dimensions of innovation and integrating various stakeholders of the innovation ecosystem to develop, adopt and implement new products, processes, services and organizational solutions. Following the principles of the integrated approach to managing innovation it is assumed that successful innovation management system should not only provide a comprehensive view of all its constituent elements, but also reflect dynamic interactions between different aspects of innovation at the firm level: technological, market and organizational. In the organizational context the integrated approach also emphasizes the importance of considering viewpoints of various actors involved in the innovation ecosystem within the industry. Understanding the environment in which the company operates as well as exploration of market trends is therefore of great relevance to be successful since sustainable growth, innovation development and competitiveness of enterprises are dependent on how they collect and analyze the information about the business environment and define their business strategies. Industry experts mention in this regard that the companies should primarily pay attention to the business environment within which they operate and formulate innovation strategies according to the appropriate industry factors $[11 ; 12-15]$.

In order to propel innovative opportunities a company needs to build and develop specific organizational capacities related to assimilation and acquisition of necessary resources as well as the capability to devise and implement appropriate innovation strategy. Following the paradigm of open innovation which can be considered as a contemporary trend in corporate innovation management, specific innovation capabilities of a company can either emerge from internal sources and be developed within the firm or they can 
originate from external sources. Essential internal capabilities for innovation include existing ideas, knowledge, experience, technologies, skills and competencies as well as the use of management tools and techniques. External innovation capabilities of a company can be related to technological and managerial solutions with respect to both exploratory and exploitative innovations. Although the mining sector is often represented as a conservative and inflexible industry with a focus on cost reduction and efficiency many of the process innovations within the industry originate from outsiders, therefore it is also the case for modern mining enterprises [8]. By opening up the internal innovation process to external ideas, information flows, knowledge and competencies and adopting them for the particular innovation project implementation, it is more likely to succeed with innovative initiatives.

Despite the fact that mining enterprises are historically inclined to operate in isolation, it is apparent from experiences worldwide that in today's business environment many companies tend to open up their innovation processes, expand cooperation and involve external partners in the accelerating internal innovation. The knowledge and technologies that can make a significant impact on the performance of mining companies are developing rapidly and mostly outside the mining industry and it can be regarded as an additional driver for participating in collaborative innovation projects related to co-creation and coinvention with technology leaders. In line with this, mining companies should keep abreast of collaborative opportunities with external partners to share innovation risks, rethink their traditional business practices and strengthen relationships with local community stakeholders. It should be noted that in the open innovation context there is a close relationship between the key actors in the mining innovation ecosystem. Typical actors in the mining innovation ecosystem include research institutions, state agencies and nongovernmental organizations, equipment and technology suppliers, analytical laboratories, consulting engineering services as well as customers that are contributing to the innovation development for sustainable outcomes and improvements in productivity. In view of the fact that mining companies are identified as a starting point of the entire value chain, they have a pivotal role to play in shaping the sectoral innovation ecosystem and should be considered as a core element of such a network.

A coordinated relationship between key actors that are involved in an integrated innovation ecosystem requires new business and management capabilities, but also creates opportunities for innovation, organizational learning and skills development. This could lead to the conclusion that mining enterprises need to capture the value of innovation across the innovation partnership and strengthen their competitiveness by leveraging and developing the innovation capabilities of the network.

\section{Conclusion}

Based on the findings of the study it can be concluded that there is a wide range of drivers for various innovation-oriented activities in the mining sector. There remain however significant challenges for innovation that can be and broadly grouped into two main categories: specific organizational difficulties which refer to insufficient or inadequate firm-level innovation capabilities and collaboration challenges that arise from the complexity of managing interactions within a networked innovation system.

There is no universal models or standards for managing innovation applicable to all industries that can ensure an effective and efficient innovation process within an organization, but despite this a number of relevant firm-level factors were identified such as leadership for innovation, corporate strategy, innovation-promoting business culture that fosters willingness to innovate, communication and collaboration skills and other 'soft' aspects which can contribute to successful innovation outcomes of a company. Critically, the sectoral specificities and current industry trends make a closed innovation approach a 
less viable option for mining companies. In line with this reasoning, a collaborative ecosystem of innovation can be considered as a means for mining enterprises to reduce risks, uncertainties and costs in the innovation process.

From a practical perspective the paper provides a basis for the identification of the key managerial areas that should be taken into account by mining companies in order to increase their innovation capabilities and improve innovation performance. Future research can examine how firm-level factors may transform the interactions between the key elements in the innovation management system of organization and how modern approaches to managing innovation can be implemented in the mining enterprises.

\section{References}

1. Innovation State of Play: Mining Edition (Deloitte Touche Tohmatsu Limited, Lindon, 2016)

2. Tracking the Trends 2019. The Top 10 Issues Transforming the Future of Mining (Deloitte Touche Tohmatsu Limited, London, 2019)

3. Innovation in Mining: Report to the 2018 International Mines Ministers Summit (IISD, Winnipeg, 2018)

4. Establishing technology leadership in the Canadian natural resources sector through industry-wide collaboration (Delphi Group, Toronto, 2017)

5. M. Kurkkio, J. Frishammar, P. Söderholm, T. Ejdemo, Mapping the Nordic Mining and Metal Industry for the Purpose of Enhancing and Developing its Innovative Capability (Luleå tekniska universitet, Helsinki, 2014)

6. T. Gstraunthaler, L. Proskuryakova, Innovation: Management, policy \& practice, 14, $32(2012)$

7. S.J. Cowell, W. Wehrmeyer, P.W. Argust, J.G.S. Robertson, Resources Policy, 25, 277 (1999)

8. T. Lager, J. Frishammar, Journal of Manufacturing Technology Management, 21, 698 (2010)

9. J. Steen, S. Macaulay, N. Kunz, J. Jackson, Understanding the Innovation Ecosystem in Mining and What the Digital Revolution Means for It. In Extracting Innovations: Mining, Energy, and Technological Change in the Digital Age. (CRC Press, New York, 2018)

10. Innovation Management. Part 1: Innovation Management System (UDPP, Kyiv, 2013)

11. L. Morris, International Management Review, 9(2), 10 (2013)

12. I. Yüksel, International Journal of Business and Management, 7(24), 52 (2012)

13. B. Boudreau-Trudel, S. Nadeau, K. Zaras. American Journal of Industrial and Business Management, 5, 161 (2015)

14. G. Hilson, V. Nayee, International Journal of Mineral Processing, 64(1), 41 (2002)

15. P. Bryant, The Case for Innovation in the Mining Industry. (Clareo: Chicago, 2015) 